\title{
Racial/ethnic differences in the utilization of infertility services: A focus on American Indian/Alaska Natives
}

\author{
Amanda E. Janitz ${ }^{a}$, Jennifer D. Peck ${ }^{a}$, and LaTasha B. Craig ${ }^{b}$ \\ A. Department of Biostatistics and Epidemiology, College of Public Health, University of Oklahoma \\ Health Sciences Center, 801 NE $13^{\text {th }}$ St., CHB 309, Oklahoma City, OK, 73104, USA \\ B. Section of Reproductive Endocrinology and Infertility, Department of Obstetrics and \\ Gynecology, University of Oklahoma Health Sciences Center, 840 Research Parkway, Suite 200, \\ Oklahoma City, OK, 73104, USA
}

\section{Abstract}

Objectives.-Previous studies have identified racial/ethnic disparities in infertility care, but patterns among American Indian/Alaska Natives (AI/AN) have not been reported. Our objective was to evaluate infertility services use in the US by race/ethnicity using data from the National Survey of Family Growth (NSFG).

Methods.-We analyzed female respondent data from the pooled NSFG cycles 2002, 2006-2010 and 2011-2013. Respondents reported use of infertility services and types of services. We calculated weighted crude and adjusted prevalence proportion ratios (PPR) and 95\% confidence intervals (95\% CI) using modified Poisson regression with robust error variances accounting for the complex survey design to compare infertility services use across race/ethnicities.

Results: Overall, $8.7 \%$ of women reported using medical services to get pregnant. The prevalence of using any medical service to help get pregnant was lower for American Indian/ Alaska Native (AI/AN) [PPR: 0.60, 95\% CI: 0.43, 0.83] and black [PPR: 0.53, 95\% CI: 0.44, 0.63] compared to white women and in Hispanic compared to non-Hispanic women [PPR: 0.57, $95 \%$ CI: $0.48,0.67]$. The prevalence of accessing treatment, testing, and advice also differed by race and ethnicity.

Conclusions for Practice: We observed disparities in accessing services to get pregnant among AI/AN and black women and reduced use of advice among Asian/Pacific Islanders compared to whites. We also observed reduced service utilization for Hispanic compared to nonHispanic women. Differential utilization of specific services suggests barriers to infertility care may contribute to reproductive health disparities among underserved populations.

Correspondence: Amanda Janitz, 801 NE $13^{\text {th }}$ St., CHB 309, Oklahoma City, OK, 73104, USA, Phone: +1-405-271-2229, Fax: +1-405-271-2068, amanda-janitz@ouhsc.edu.

Amanda E. Janitz: amanda-janitz@ouhsc.edu

Jennifer D. Peck: jennifer-peck@ouhsc.edu

LaTasha B. Craig: latasha-craig@ouhsc.edu

Conflict of Interest: The authors declare that they have no conflict of interest. 


\section{Keywords}

Infertility; services; race; ethnicity; Indians; North American

\section{Objectives}

Access to infertility services is a public health priority, according to the Centers for Disease Control and Prevention (CDC), and disparities exist for racial/ethnic minorities in utilization of infertility services (Butts \& Seifer, 2010; Centers for Disease Control and Prevention, 2014; Chin, Howards, Kramer, Mertens, \& Spencer, 2015; Feinberg, Larsen, Catherino, Zhang, \& Armstrong, 2006; Inhorn \& Fakih, 2006; McCarthy-Keith et al., 2010). The 20062010 National Survey of Family Growth (NSFG) reported that $8.7 \%$ of respondents had ever used medical help to get pregnant, but fewer Hispanics and non-Hispanic blacks reported using help to get pregnant compared to non-Hispanic whites (Chandra, Copen, \& Stephen, 2014). However, American Indian/Alaska Native (AI/AN) women were not assessed. The 2012 Agency for Healthcare Research and Quality National Healthcare Disparities Report found that AI/ANs had poorer quality of care and worse access to care than whites across a broad set of measures, although infertility services were not specifically addressed (Agency for Healthcare Research and Quality \& U.S. Department of Health and Human Services, 2013). Studies indicate that those who utilize infertility services are more likely to be older, highly educated, married, non-Hispanic whites compared to those who do not utilize these services (Chandra, Copen, \& Stephen, 2013; Greil, McQuillan, \& Sanchez, 2014; Nachtigall, 2006; Staniec \& Webb, 2007). These disparities in infertility service utilization may be attributed to the cost of care and lack of health insurance for affordable diagnostic testing and treatment (Smith et al., 2011). Thus, barriers to infertility care may disproportionately affect underserved populations, but no study to date has reported on the prevalence of infertility service use in $\mathrm{AI} / \mathrm{AN}$ populations.

Prevention of reproductive health disparities requires monitoring race-specific infertility prevalence, treatment patterns and related risk factors to identify, guide, implement and monitor effective public health action strategies to safeguard reproductive health (Centers for Disease Control and Prevention, 2014). This study addresses this need by evaluating racial/ ethnic disparities in infertility service use in a nationally representative sample, providing the first assessment to include the AI/AN population.

\section{Methods}

\section{Study Design and Population.}

We conducted a secondary analysis of cross-sectional data from the NSFG to examine racial/ethnic variation in the utilization of infertility services, with emphasis on the AI/AN population (Centers for Disease Control \& Prevention, 2015). The NSFG is a national survey conducted by the CDC's National Center for Health Statistics and the only US population-based survey on infertility and receipt of infertility services (Lepkowski et al., 2006; Lepkowski, Mosher, Davis, Groves, \& Van Hoewyk, 2010). Informed consent was obtain for all participants (Centers for Disease Control \& Prevention, 2015). The NSFG 
survey cycles 2002, 2006-2010 and 2011-2013 gathered information on pregnancy, infertility, health status and health services among men and women aged 15-44 years. Respondent selection was based on nationally representative, multistage area probability samples from areas across the United States (Lepkowski et al., 2006; Lepkowski et al., 2010). For this analysis, we included female respondent data from the pooled NSFG data given that the female questions provide greater detail on types of medical services to achieve pregnancy and are generally regarded as less prone to reporting errors than men (Chandra et al., 2013).

\section{Race and Ethnicity.}

The NSFG assessed race, ethnicity, and other covariates through self-report. The NSFG allowed respondents to select up to four races but were asked which one race best described them, which we used to define race in this analysis. Racial groups were categorized as 1) AI/AN; 2) Asian, Native Hawaiian or Pacific Islander (Asian/PI); 3) black and 4) white. Ethnicity was assessed separately as Hispanic or non-Hispanic (NH). Because race data for AI/ANs and Asian/PIs are restricted from public access by NSFG, we accessed data through the National Center for Health Statistics Research Data Center. Because of the restricted status of the detailed racial information, protections to avoid disclosure prevented the use of combined race/ethnicity classifications in these analyses (e.g., non-Hispanic white, etc.).

\section{Outcome Measures of Infertility Service Use.}

In the selected survey cycles, the NSFG asked two types of infertility services questions addressing whether the respondent or her partner: 1) ever used any medical help to get pregnant, which excludes those seeking medical help to prevent miscarriage, and 2) ever used infertility services, which includes help to get pregnant and help to prevent miscarriage (Chandra et al., 2014). Questions regarding use of any medical services to help get pregnant or any infertility services were asked of all women if they reported having sexual intercourse with a male and were 18 years of age or older at the time of the interview, regardless of fertility problems. Specific types of services were only asked of women who reported any use of medical help to get pregnant. Due to small sample sizes for specific types of services within race and ethnicity groups, we analyzed three categories of infertility services: treatment, testing, and advice. Treatment included drugs to improve ovulation, surgery to correct blocked tubes, artificial insemination, in vitro fertilization or other assisted reproduction, and surgery for endometriosis or fibroids. Testing included infertility testing on either the female respondent or her partner. Advice was a separate service option provided on the original NSFG survey and was not further defined.

\section{Covariates.}

Demographic covariates obtained from the survey included age at interview, marital status, income, poverty, education, metropolitan residence, religion, current insurance and body mass index. Covariates addressing reproductive history included parity, history of treatment for pelvic inflammatory disease, gynecologic problems, and fecundity. Gynecologic problems were defined as the presence of ovulation problems, uterine fibroids, or endometriosis. Fecundity was classified as surgically sterile, impaired fecundity (i.e., 
impossible or difficult to carry a baby to term or $\geq 3$ year interval without conception when married or cohabiting and not using contraception), or fecund.

\section{Statistical Analysis.}

We compared prevalence of infertility services use by race and ethnicity and other demographic covariates by calculating weighted prevalence proportions and $95 \%$ confidence intervals (CI) accounting for the complex sampling of the NSFG and imputation of missing values (Lepkowski et al., 2006; Lepkowski et al., 2010). To determine if there were statistically significant differences in the demographic covariates by use of services, we used weighted Chi-Square tests. The prevalence of services use was compared across race/ ethnicity groups using modified Poisson regression with robust error variance accounting for the complex survey design (Hale, Thompson, \& Darden, 2013). We estimated weighted prevalence proportion ratios (PPR) and 95\% CIs controlling for covariates of interest. Our analyses examined several measures of service utilization: 1) the NSFG constructed variable reflecting ever use of medical help to get pregnant, 2) specific types of services among women who ever used medical services to help get pregnant, 3) ever use of medical help to get pregnant restricted to infertile women, and 4) ever use of infertility services. The NSFG defined infertility as greater than 12 months of intercourse without pregnancy among married or cohabiting respondents in a continuous relationship for 12 months or more with no use of contraception (Chandra et al., 2013).

We controlled our multivariable models for age at interview, marital status, income, poverty, education, metropolitan status, history of treatment for pelvic inflammatory disease, gynecologic problems, religion, parity, current insurance, body mass index, and fecundity. This study was reviewed by the Institutional Review Board at the University of Oklahoma Health Sciences Center.

\section{Results}

In the NSFG survey cycles 2002, 2006-2010, and 2011-2013 combined, 8.7\% [95\% CI: 8.1, $9.3, \mathrm{n}=1824$ ] of women used any medical help to get pregnant (Table 1). We observed statistically significant differences in the distribution of all demographic factors between those who have and have not ever used any medical help to get pregnant, with the exception of metropolitan status. Women using any medical help to get pregnant had an older age distribution compared to those not utilizing care. In addition, women who used any medical help to get pregnant were more likely to be married to a person of the opposite sex, have 16 or more years of education, have private insurance, lower poverty, and higher income. There was also a higher percentage of women reporting gynecologic problems and impaired fecundity among those using any medical help to get pregnant compared to those who did not.

The race-specific prevalence of using medical help to get pregnant was lower among AI/ANs [5.8\% (95\% CI: 3.9, 7.7)] and blacks [5.1\% (95\% CI: 4.2, 5.9)] compared to whites [9.6\% (95\% CI: 8.9, 10.4)], with Asian/PIs [9.9\% (95\% CI: 6.6, 13.1)] similar to whites (Table 2). Thus, when compared to white women, $40 \%$ fewer AI/AN women [PPR: 0.60, 95\% CI: $0.43,0.83$ ] and 47\% fewer black women [PPR: 0.53, 95\% CI: 0.44, 0.63] utilized 
care. When adjusted for demographic and reproductive characteristics, differences in the use of medical help to get pregnant were no longer observed between AI/AN and white women [PPR: 1.04, 95\% CI: 0.81, 1.34]. In contrast, disparities between blacks and whites remained after covariate adjustment but were attenuated, with black women exhibiting a $23 \%$ lower prevalence of using any medical help to get pregnant compared to whites [PPR: 0.77, 95\% CI: 0.64, 0.92]. We observed no differences for Asian/PI women compared to whites in unadjusted or adjusted analyses. When assessing ethnicity, Hispanic women had a lower unadjusted prevalence of using medical help to get pregnant compared to non-Hispanic women [5.3\% (95\% CI: 4.5, 6.1) vs. 9.4\% (95\% CI: 8.7, 10.1; PPR: 0.57 (95\% CI: 0.48, 0.67)]; however, the PPR approached 1.0 after adjustment for covariates.

In our analyses of specific service types among women who used medical help to get pregnant, the prevalence of treatment, testing or seeking advice to get pregnant did not differ for $\mathrm{AI} / \mathrm{AN}$ women when compared to white women. Black women had lower prevalence of receiving treatment [PPR: $0.78,95 \%$ CI: $0.63,0.97]$ and testing [PPR: $0.77,95 \%$ CI: 0.63 , 0.93] compared to white women, which we also observed among Hispanic compared to nonHispanic women [Treatment PPR: 0.70, 95\% CI: 0.57, 0.87; Testing PPR: 0.76, 95\% CI: $0.64,0.91]$ (Table 2). These associations were attenuated after controlling for covariates and, with the exception of the prevalence of treatment among blacks, the upper bound of the confidence interval narrowly exceeded 1.0. Black [PPR: 0.85, 95\% CI: 0.74, 0.97] and Asian/PI women [PPR: 0.68, 95\% CI: 0.49, 0.97], had a 15-32\% lower adjusted prevalence of seeking advice for infertility compared to white women.

When restricted to infertile women $(n=784)$, the prevalence of using any medical help to get pregnant was similar in magnitude for white and AI/AN women but ranged from a low of $31.1 \%$ [95\% CI: 20.0, 42.2] among black women to a high of $41.4 \%$ [95\% CI: $18.9,63.9$ ] among Asian/PI women (Table 3). Racial differences among infertile women did not achieve statistical significance in either unadjusted or adjusted analyses. However, we observed a significantly elevated prevalence of using any medical help to get pregnant among Hispanic women compared to non-Hispanic women [PPR: 1.33, 95\% CI: 1.06, 1.67] after controlling for demographic and reproductive characteristics.

When evaluating the use of any infertility services (including help to prevent miscarriage), we observed that $12.6 \%$ of all women utilized services [95\% CI: $11.9 \%, 13.2 \%, \mathrm{n}=2664$ ]. Patterns of comparisons by race and ethnicity remained similar but were mostly attenuated when compared to evaluations that excluded seeking help to prevent miscarriage (Table 4). After adjusting for covariates, AI/AN women had a 14\% higher prevalence of using any infertility services compared to whites, though differences were not statistically significant [PPR: 1.14, 95\% CI: 0.93, 1.40] (Table 4). In contrast, black women had a lower prevalence of using any infertility services [PPR: $0.87,95 \%$ CI: $0.74,1.02]$ compared to whites.

\section{Conclusions for Practice}

We observed disparities among AI/AN and black women compared to white women and Hispanic compared to non-Hispanic women for use of any medical help to get pregnant, type of medical services received, and any infertility service. Asian/PI women had a similar 
prevalence of using services compared to whites, with the exception of a lower prevalence of seeking advice.

Previous studies have not evaluated utilization of infertility care among AI/AN women, who generally have poorer access to care for a range of health issues (Cobb, Espey, \& King, 2014). We observed disparities among AI/AN women in use of services in the unadjusted analysis, which reflects the actual magnitude of the gap in healthcare utilization experienced by this population. However, this differential in utilization of infertility services was attenuated after accounting for differences in participant characteristics, indicating that socioeconomic and clinical factors may account for a large proportion of the disparity.

While this is the first study to report disparities in infertility services use for AI/AN women, our results for other race/ethnic groups are similar to recent studies. In a population-based cohort of women in the state of Georgia, Chin et al. (2015) observed that black women were $48 \%$ less likely to seek care for help getting pregnant compared to white women [RR: 0.54, $95 \%$ CI: $0.35,0.81]$. Also consistent with our results, the authors observed that the association between infertility service utilization and race was weaker and no longer statistically significant when restricted to infertile women, indicating reduced disparities among infertile women [Black v. white RR: $0.76,95 \%$ CI: $0.52,1.11$ ] compared to the results observed among all women.

Chandra et al. (2014) reported on infertility services utilization from the combined 1995, 2002, and 2006-2010 NSFG cycles. The authors reported disparities among all Hispanic [Odds Ratio (OR): 0.64, 95\% CI: 0.54, 0.76] and non-Hispanic black women [OR: 0.70, $95 \%$ CI: $0.59,0.83$ ] utilizing medical services to help achieve pregnancy compared to nonHispanic white women. In contrast to our results, the disparities persisted when limiting the analysis to women with current fertility problems aged 25-44 [Hispanic OR: $0.73,95 \%$ CI: 0.56, 0.96; non-Hispanic black OR: 0.72, 95\% CI 0.54, 0.97], whereas we observed increased utilization for Hispanic women with infertility. However, our comparison groups differed from those in Chandra et al. (2014) since we analyzed race and ethnicity as separate variables and included a wider range of ages (15-44 years). We also defined infertility as 12 or more months of intercourse without pregnancy and without contraception among those who were currently married or cohabiting, which differed from the broader definition used by the authors (either impaired fecundity or 12-month infertility).

Racial/ethnic disparities in infertility service utilization may be attributed to the cost of care and lack of health insurance for affordable diagnostic testing and treatment (Adashi \& Dean; Quinn \& Fujimoto, 2016). In a recent analysis of the CDC's National Assisted Reproductive Technology Surveillance System, Dieke, Zhang, Kissin, Barfield, and Boulet (2017) noted that in states with insurance mandates for in vitro fertilization treatments, use of assisted reproductive technology (ART) was higher for each race/ethnic group studied compared to states without mandates (non-Hispanic [NH] Asian/Pacific Islander: 1.5, NH white 2.1, NH black 2.2, Hispanic 1.9, NH AI/AN 4.8 times higher). The particularly large disparity for $\mathrm{NH}$ AI/AN ART use in states without insurance mandates indicates the importance of socioeconomic barriers for these families. In a study of US military personnel, disparities in infertility services use were reduced for black women, with the percentage of black women 
seeking infertility care in the Department of Defense [DoD] ART program similar to the percentage of black women in the DoD (17.4\% v. $19.1 \%$, respectively). ART in the DoD is provided at lower cost than in the civilian population (Feinberg et al., 2006). However, a disparity remained in Hispanic women utilizing services compared to the percentage of Hispanic women in the DoD (3.9\% v. 9.0\%, respectively). Similarly, Jain (2006) observed disparities in minority patients seeking care at an infertility clinic in a state with mandated coverage for infertility treatment (Massachusetts). The authors reported longer duration of infertility among black patients (Jain, 2006) and disparities in the distribution of race, education, and income among survey respondents compared to the demographic distribution in the state (Jain \& Hornstein, 2005).

Economic issues may not fully explain the reasons for persistent disparities for Hispanic women, though the reasons for this are not clear (Feinberg et al., 2006; Feinberg, Larsen, Wah, Alvero, \& Armstrong, 2007; Greil et al., 2014). In a qualitative study, Greil et al. (2014) reported that factors related to secondary infertility, ethical concerns about infertility treatment, definition of "trying to get pregnant," support of family and friends for infertility treatment, and a lower value of motherhood may also contribute to uptake of infertility services in black and Hispanic women. These results indicate that barriers to seeking infertility care are complex and deserve further exploration.

A strength of our study was the ability to combine the NSFG survey data over multiple survey cycles, ranging a span of 12 years. This provided a unique opportunity to examine utilization of infertility services among racial/ethnic groups including the $\mathrm{AI} / \mathrm{AN}$ population, whose numbers in clinical and population-based studies are frequently too limited to assess separately from other racial groups. The number of AI/ANs included in the NSFG is small compared to other racial/ethnic groups, including blacks and Hispanics who are oversampled in the NSFG (Lepkowski et al., 2010). Although the AI/AN population in the US is small $(0.8 \%)$, the percentage of AI/ANs varies greatly across the US from $0.2 \%$ in West Virgina to 13.8\% in Alaska (United States Census Bureau, 2017). Inclusion of AI/ANs in the NSFG may vary by different AI/AN populations and regions sampled for each survey cycle, but the ability to pool multiple cycles may improve generalizability of the results to the AI/AN population. However, cultural factors related to infertility were not explored within the NSFG.

One limitation of this study is the cross-sectional nature of the NSFG data. Women were surveyed regarding whether they have ever sought medical service to get pregnant and/or prevent miscarriage. Because we only have information from one point in time for each woman, we are unable to evaluate differences in the duration of infertility on service utilization. We also were unable to obtain information on the patterns of care for women, including the time spent on different types of infertility treatment or fertility outcomes. Furthermore, survey non-response is a potential source of bias. To reduce this risk, the NSFG implemented a two-phase design, with the second phase of the study including selection of a probability sample of non-responders for interview from the first phase of the study (Lepkowski et al., 2010). Because of the small number of AI/AN and Asian/PI infertile women in the NSFG (Table 3), our estimates are imprecise as evidenced by wide confidence intervals and should be interpreted with caution (Klein, Proctor, Boudreault, \& 
Turczyn, 2002). The cross-sectional nature of this survey also does not capture the diversity within race and ethnic groups in the US. For example, there are over 500 federallyrecognized tribes in the US, all with different cultures and factors related to infertility and other health care utilization (National Congress of American Indians, 2015). Another limitation of our study is a lack of information on cultural reasons for using or not using infertility services. Qualitative data may be needed to better understand the factors related to infertility care, particularly culturally-specific values. Future interventions to reduce disparities should address the costs of treatment, accessibility of care, health education, and preventable infertility (Quinn \& Fujimoto, 2016). In addition, studies should further explore outcomes among AI/AN women seeking care for infertility, an area in which research has also been limited but suggestive of lower fecundability among AI/AN patients undergoing intrauterine insemination treatment (Craig et al., 2018).

In conclusion, we observed disparities in infertility service utilization for AI/AN and black women and, more specifically, for services providing medical advice among Asian/PI and black women compared to whites in the NSFG. With the exception of AI/ANs, these observed disparities remained after accounting for demographic characteristics and reproductive history. Further evaluation of factors related to utilization of infertility services, including differences by socioeconomic status, should be explored in future studies. The CDC's National Public Health Action Plan on infertility highlights the need to understand factors related to utilization of infertility services (Centers for Disease Control and Prevention, 2014). As the first study to evaluate NSFG data on infertility services use by race/ethnicity including $\mathrm{AI} / \mathrm{AN}$ women, these results contribute to the limited knowledge on infertility service utilization for this diverse population. Differential utilization of specific services suggests barriers to infertility care may contribute to reproductive health disparities among underserved populations.

\section{Acknowledgements:}

This project is supported by the Health Resources and Services Administration (HRSA) of the U.S. Department of Health and Human Services (HHS) under 1 R40MC29449-01-00 and the Oklahoma Shared Clinical and Translational Resource Institute NIGMS U54 GM104938. The information, content and/or conclusions are those of the authors and should not be construed as the official position or policy of, nor should any endorsements be inferred by HRSA, HHS or the U.S. The findings and conclusions in this paper are those of the author(s) and do not necessarily represent the views of the Research Data Center, the National Center for Health Statistics, or the Centers for Disease Control and Prevention.

\section{References}

Adashi EY, \& Dean LA Access to and use of infertility services in the United States: framing the challenges. Fertility and Sterility, 105(5), 1113-1118. doi:10.1016/j.fertnstert.2016.01.017

Agency for Healthcare Research and Quality, \& U.S. Department of Health and Human Services. (2013). 2012 National Healthcare Disparities Report. Retrieved from

Butts SF, \& Seifer DB (2010). Racial and ethnic differences in reproductive potential across the life cycle. Fertility and Sterility, 93(3), 681-690. doi:10.1016/j.fertnstert.2009.10.047 [PubMed: 19939362]

Centers for Disease Control \& Prevention. (2015). National Survey of Family Growth. Retrieved from https://www.cdc.gov/nchs/nsfg/index.htm

Centers for Disease Control and Prevention. (2014). National Public Health Action Plan for the Detection, Prevention, and Management of Infertility. Retrieved from Atlanta, GA: 
Chandra A, Copen CE, \& Stephen EH (2013). Infertility and impaired fecundity in the United States, 1982-2010: data from the National Survey of Family Growth. Natl Health Stat Report(67), 1-18.

Chandra A, Copen CE, \& Stephen EH (2014). Infertility service use in the United States: data from the National Survey of Family Growth, 1982-2010. Natl Health Stat Report(73), 1-21.

Chin HB, Howards PP, Kramer MR, Mertens AC, \& Spencer JB (2015). Racial Disparities in Seeking Care for Help Getting Pregnant. Paediatric and Perinatal Epidemiology, 29(5), 416-425. doi: 10.1111/ppe.12210 [PubMed: 26201443]

Cobb N, Espey D, \& King J (2014). Health Behaviors and Risk Factors Among American Indians and Alaska Natives, 2000-2010. American Journal of Public Health, e1-e9. doi: 10.2105/AJPH. 2014.301879

Craig LB, Weedin EA, Walker WD, Janitz AE, Hansen KR, \& Peck JD (2018). Racial and Ethnic Differences in Pregnancy Rates Following Intrauterine Insemination with a Focus on American Indians. Racial and Ethnic Health Disparities, In Press. doi:10.1007/s40615-017-0456-8

Dieke AC, Zhang Y, Kissin DM, Barfield WD, \& Boulet SL (2017). Disparities in Assisted Reproductive Technology Utilization by Race and Ethnicity, United States, 2014: A Commentary. J Womens Health (Larchmt), 26(6), 605-608. doi: 10.1089/jwh.2017.6467 [PubMed: 28586255]

Feinberg EC, Larsen FW, Catherino WH, Zhang J, \& Armstrong AY (2006). Comparison of assisted reproductive technology utilization and outcomes between Caucasian and African American patients in an equal-access-to-care setting. Fertility and Sterility, 85(4), 888-894. doi:10.1016/ j.fertnstert.2005.10.028 [PubMed: 16580370]

Feinberg EC, Larsen FW, Wah RM, Alvero RJ, \& Armstrong AY (2007). Economics may not explain Hispanic underutilization of assisted reproductive technology services. Fertil Steril, 88(5), 1439 1441. doi:10.1016/j.fertnstert.2007.01.031 [PubMed: 17561005]

Greil AL, McQuillan J, \& Sanchez D (2014). Does fertility-specific distress vary by race/ethnicity among a probability sample of women in the United States? J Health Psychol. doi: $10.1177 / 1359105314524970$

Hale JJ, Thompson DM, \& Darden PM (2013). Calculating subset weighted analysis using PROC SURVEYFREQ and GENMOD (Paper 272-2013). SAS Global Forum.

Inhorn MC, \& Fakih MH (2006). Arab Americans, African Americans, and infertility: barriers to reproduction and medical care. Fertil Steril, 85(4), 844-852. doi: 10.1016/j.fertnstert.2005.10.029 [PubMed: 16580363]

Jain T (2006). Socioeconomic and racial disparities among infertility patients seeking care. Fertility and Sterility, 85(4), 876-881. doi:10.1016/j.fertnstert.2005.07.1338 [PubMed: 16580368]

Jain T, \& Hornstein MD (2005). Disparities in access to infertility services in a state with mandated insurance coverage. Fertil Steril, 84(1), 221-223. doi:10.1016/j.fertnstert.2005.01.118 [PubMed: 16009188]

Klein RJ, Proctor SE, Boudreault MA, \& Turczyn KM (2002). Healthy People 2010 Criteria for Data Suppression: Statistical Notes, no 24. Retrieved from Hyattsville, MD: https://www.cdc.gov/nchs/ data/statnt/statnt24.pdf

Lepkowski JM, Mosher MJ, Davis KE, Groves RM, van Hoewyk J, \& Willem J (2006). National Survey of Family Growth, Cycle 6: Sample design, weighting, imputation, and variance estimation. Vital Health Stat, 2(142), 1-82.

Lepkowski JM, Mosher WD, Davis KE, Groves RM, \& Van Hoewyk J (2010). The 2006-2010 National Survey of Family Growth: Sample design and analysis of a continuous survey. Vital Health Stat, 2(150), 1-36.

McCarthy-Keith DM, Schisterman EF, Robinson RD, O’Leary K, Lucidi RS, \& Armstrong AY (2010). Will decreasing assisted reproduction technology costs improve utilization and outcomes among minority women? Fertility and Sterility, 94(7), 2587-2589. doi:10.1016/j.fertnstert.2010.02.021 [PubMed: 20356585]

Nachtigall RD (2006). International disparities in access to infertility services. Fertil Steril, 85(4), 871875. doi:10.1016/j.fertnstert.2005.08.066 [PubMed: 16580367]

National Congress of American Indians. (2015). Tribal Nations and the United States: An Introduction. Retrieved from Washington DC:http://www.ncai.org/attachments/ 
PolicyPaper_VmQazPEqbvZDMeaDvbupWTSZLmzyz BKOknQRXnUyoVMoyFkEWGH_Tribal $\% 20$ Nations \%20and\%20the\%20United\%20States An\%20Introduction.pdf

Quinn M, \& Fujimoto V (2016). Racial and ethnic disparities in assisted reproductive technology access and outcomes. Fertility and Sterility, 105(5), 1119-1123. doi:10.1016/j.fertnstert. 2016.03.007 [PubMed: 27054308]

Smith JF, Eisenberg ML, Glidden D, Millstein SG, Cedars M, Walsh TJ, . . Katz PP (2011). Socioeconomic disparities in the use and success of fertility treatments: analysis of data from a prospective cohort in the United States. Fertil Steril, 96(1), 95-101. doi:10.1016/j.fertnstert. 2011.04.054 [PubMed: 21616487]

Staniec JFO, \& Webb NJ (2007). Utilization of infertility services: how much does money matter? Health Serv Res, 42(3 Pt 1), 971-989. doi:10.1111/j.1475-6773.2006.00640.x [PubMed: 17489899]

United States Census Bureau. (2017). Race: 2011-2015 American Community Survey 5-Year Estimates. Retrieved from https://factfinder.census.gov/faces/tableservices/jsf/pages/ productview.xhtml?pid=ACS_15_5YR_B02001\&prodType=table 


\section{Significance}

Access to infertility services is a public health priority, according to the Centers for Disease Control and Prevention (CDC), and disparities exist for racial/ethnic minorities in utilization of infertility services. We observed disparities in accessing services to get pregnant among American Indian/Alaska Native, black, and Hispanic women. These results suggest barriers to infertility care may contribute to reproductive health disparities among underserved populations. 
Table 1.

Distribution of participant characteristics by use of medical services to help get pregnant.

\begin{tabular}{|c|c|c|c|c|c|}
\hline & \multicolumn{2}{|c|}{$\begin{array}{l}\text { Ever Used Medical Services to } \\
\text { Achieve Pregnancy }\end{array}$} & \multicolumn{2}{|c|}{$\begin{array}{l}\text { Never Used Medical Services to } \\
\text { Achieve Pregnancy }\end{array}$} & \\
\hline & \multicolumn{2}{|c|}{$\mathrm{N}=\mathbf{1 , 8 2 4}$} & \multicolumn{2}{|c|}{$\mathrm{N}=\mathbf{2 1 , 9 1 7}$} & \\
\hline & $\mathbf{N}$ & $\begin{array}{l}\text { Weighted \% } \\
\text { [95\% CI] }\end{array}$ & $\mathbf{N}$ & $\begin{array}{l}\text { Weighted \% } \\
\text { [95\% CI] }\end{array}$ & p-value \\
\hline Total & 1824 & $8.7[8.1,9.3]$ & 21917 & $91.3[90.7,91.9]$ & $<0.0001$ \\
\hline \multicolumn{6}{|l|}{ Age } \\
\hline $15-24$ years & 126 & $5.4[4.1,6.8]$ & 6984 & $30.2[29.0,31.3]$ & $<0.0001$ \\
\hline $25-29$ years & 279 & $14.2[11.8,16.5]$ & 4453 & $17.9[17.2,18.7]$ & \\
\hline $30-34$ years & 409 & $22.3[19.7,24.9]$ & 3969 & $16.9[16.1,17.6]$ & \\
\hline $35-39$ years & 525 & $29.2[26.1,32.3]$ & 3356 & $17.0[16.2,17.9]$ & \\
\hline $40-44$ years & 481 & $28.9[25.8,32.0]$ & 3150 & $18.0[17.1,18.9]$ & \\
\hline \multicolumn{6}{|l|}{ Race } \\
\hline White & 1393 & $82.6[80.0,85.2]$ & 14406 & $74.1[72.3,76.0]$ & $<0.0001$ \\
\hline Black & 258 & $9.1[7.5,10.7]$ & 5094 & $16.3[15.0,17.6]$ & \\
\hline Asian/Pacific Islander & 80 & $5.0[3.3,6.8]$ & 915 & $4.4[3.9,4.9]$ & \\
\hline American Indian/Alaska Native & 74 & $3.3[2.2,4.4]$ & 1295 & $5.2[3.8,6.6]$ & \\
\hline \multicolumn{6}{|l|}{ Hispanic Ethnicity } \\
\hline Hispanic & 307 & $10.4[8.5,12.3]$ & 5000 & $17.6[15.8,19.5]$ & $<0.0001$ \\
\hline Non-Hispanic & 1517 & $89.6[87.7,91.5]$ & 16917 & $82.4[80.5,84.2]$ & \\
\hline \multicolumn{6}{|l|}{ Education } \\
\hline $0-11$ years & 190 & $6.9[5.6,8.2]$ & 4117 & $16.4[15.4,17.3]$ & $<0.0001$ \\
\hline 12 years & 290 & $14.9[12.5,17.4]$ & 4968 & $21.7[20.8,22.6]$ & \\
\hline $13-15$ years & 625 & $32.2[28.8,35.5]$ & 7409 & $34.0[32.9,35.1]$ & \\
\hline $16+$ years & 719 & $46.0[42.4,49.5]$ & 5423 & $27.9[26.5,29.4]$ & \\
\hline \multicolumn{6}{|l|}{ Marital Status } \\
\hline $\begin{array}{l}\text { Currently Married to a Person of the } \\
\text { Opposite Sex }\end{array}$ & 1307 & $79.7[77.2,82.3]$ & 7454 & $41.5[40.1,43.0]$ & $<0.0001$ \\
\hline $\begin{array}{l}\text { Not Married but Living with Opposite } \\
\text { Sex Partner }\end{array}$ & 125 & $6.7[5.0,8.4]$ & 2819 & $13.1[12.3,13.9]$ & \\
\hline Widowed & 9 & $0.5[0.1,1.0]$ & 104 & $0.4[0.3,0.6]$ & \\
\hline Divorced or Annulled & 165 & $6.0[4.8,7.2]$ & 1533 & $6.5[6.0,7.0]$ & \\
\hline $\begin{array}{l}\text { Separated for Reasons of Marital } \\
\text { Discord }\end{array}$ & 79 & $2.7[1.8,3.5]$ & 849 & $3.2[2.8,3.5]$ & \\
\hline Never Been Married & 139 & $4.3[3.1,5.5]$ & 9158 & $35.3[34.0,36.5]$ & \\
\hline \multicolumn{6}{|l|}{ Current Insurance } \\
\hline Private Insurance & 1370 & $81.6[79.2,83.9]$ & 12055 & $61.1[59.4,62.8]$ & $<0.0001$ \\
\hline $\begin{array}{l}\text { Medicaid, CHIP, Other State-Sponsored } \\
\text { Plan }\end{array}$ & 166 & $5.6[4.3,6.8]$ & 4165 & $14.5[13.5,15.5]$ & \\
\hline $\begin{array}{l}\text { Medicare, Military Health Care, or Other } \\
\text { Government Health Care }\end{array}$ & 63 & $3.2[1.9,4.4]$ & 936 & $3.9[3.0,4.8]$ & \\
\hline
\end{tabular}

Matern Child Health J. Author manuscript; available in PMC 2020 January 01. 


\begin{tabular}{|c|c|c|c|c|c|}
\hline & \multicolumn{2}{|c|}{$\begin{array}{l}\text { Ever Used Medical Services to } \\
\text { Achieve Pregnancy }\end{array}$} & \multicolumn{2}{|c|}{$\begin{array}{l}\text { Never Used Medical Services to } \\
\text { Achieve Pregnancy }\end{array}$} & \\
\hline & \multicolumn{2}{|c|}{$\mathrm{N}=\mathbf{1 , 8 2 4}$} & \multicolumn{2}{|c|}{$\mathrm{N}=\mathbf{2 1 , 9 1 7}$} & \\
\hline & $\mathbf{N}$ & $\begin{array}{l}\text { Weighted \% } \\
\text { [95\% CI] }\end{array}$ & $\mathbf{N}$ & $\begin{array}{l}\text { Weighted \% } \\
\text { [95\% CI] }\end{array}$ & p-value \\
\hline $\begin{array}{l}\text { Single-Service Plan, Indian Health } \\
\text { Service, Uninsured }\end{array}$ & 225 & $9.7[7.9,11.4]$ & 4730 & $20.5[19.3,21.7]$ & \\
\hline \multicolumn{6}{|l|}{ Presence of Gynecologic Problems ${ }^{a}$} \\
\hline No & 713 & $38.4[34.9,41.9]$ & 17756 & $80.8[79.9,81.7]$ & $<0.0001$ \\
\hline Yes & 1111 & $61.6[58.1,65.1]$ & 4161 & $19.2[18.3,20.1]$ & \\
\hline
\end{tabular}

Poverty Status

\begin{tabular}{|l|r|r|r|r|r|}
\hline$<150$ percent of poverty level & 393 & $16.3[14.1,18.4]$ & 8885 & $35.6[34.2,37.1]$ & $<0.0001$ \\
\hline $150-299$ percent of poverty level & 499 & $25.4[22.6,28.2]$ & 6077 & $28.1[27.1,29.1]$ & \\
\hline 2300 percent of poverty level & 932 & $58.3[55.1,61.5]$ & 6955 & $36.3[34.8,37.7]$ & \\
\hline
\end{tabular}

\section{Metropolitan Status}

\begin{tabular}{|l|r|r|r|r|r|}
\hline $\begin{array}{c}\text { Principal City of Metropolitan } \\
\text { Statistical Area [MSA] }\end{array}$ & 734 & $35.3[31.5,39.0]$ & 9606 & $38.6[36.0,41.1]$ & 0.17 \\
\hline Other MSA & 807 & $47.1[42.3,51.9]$ & 9089 & $43.8[41.0,46.6]$ & \\
\hline Not MSA & 283 & $17.6[13.4,21.9]$ & 3222 & $17.7[15.2,20.1]$ & \\
\hline
\end{tabular}

\section{Religion}

\begin{tabular}{|l|r|r|r|r|r|}
\hline No Religion & 248 & $12.7[10.3,15.0]$ & 4087 & $18.4[17.3,19.5]$ & 0.0003 \\
\hline Catholic & 497 & $25.6[22.7,28.5]$ & 5633 & $25.1[23.6,26.5]$ & \\
\hline Protestant & 918 & $53.5[49.9,57.1]$ & 10605 & $48.7[47.1,50.3]$ & \\
\hline Other Religions & 161 & $8.3[6.0,10.7]$ & 1592 & $7.9[6.3,9.4]$ & \\
\hline
\end{tabular}

Parity

\begin{tabular}{|l|r|r|r|r|r|}
\hline 0 & 598 & $31.4[28.1,34.6]$ & 8906 & $40.0[38.6,41.4]$ & $<0.0001$ \\
\hline 1 & 472 & $24.5[21.6,27.3]$ & 4304 & $17.8[17.1,18.5]$ & \\
\hline 2 & 464 & $26.2[23.3,29.1]$ & 4599 & $22.0[21.1,23.0]$ & \\
\hline$\geq 3$ & 290 & $18.0[15.1,20.9]$ & 4108 & $20.2[19.1,21.3]$ & \\
\hline
\end{tabular}

\section{Treatment for Pelvic Inflammatory Disease}

\begin{tabular}{|l|r|r|r|r|r|}
\hline No & 1671 & $93.3[91.9,94.8]$ & 20854 & $95.6[95.2,96.0]$ & 0.0004 \\
\hline Yes & 153 & $6.7[5.2,8.1]$ & 1063 & \multicolumn{3}{|c|}{$4.4[4.0,4.8]$} & \\
\hline BMI & 37 & $2.3[1.2,3.4]$ & 368 & \multicolumn{5}{|c|}{$2.0[1.7,2.4]$} & 0.0002 \\
\hline$<18.5$ & 580 & $39.2[35.5,42.8]$ & 7133 & $41.3[39.9,42.6]$ & \\
\hline $18.5-24.9$ & 415 & $21.3[18.9,23.8]$ & 4866 & $26.7[25.6,27.8]$ & \\
\hline $25.0-29.9$ & 283 & $17.7[14.9,20.4]$ & 2869 & $15.0[14.2,15.9]$ & \\
\hline $30.0-34.9$ & 359 & $19.5[16.9,22.2]$ & 3038 & $15.0[14.1,15.8]$ & \\
\hline 235.0 & & & & & \\
\hline Total Family Annual Income & 224 & $9.1[7.4,10.8]$ & 5554 & $20.6[19.6,21.6]$ & $<0.0001$ \\
\hline$<\$ 15,000$ & 392 & $16.0[13.9,18.1]$ & 6344 & $26.9[25.8,28.0]$ & \\
\hline$\$ 15,000$ to $\$ 34,999$ & 440 & $23.9[20.8,27.0]$ & 4994 & $23.9[22.9,24.9]$ & \\
\hline$\$ 35,000$ to $\$ 59,999$ & & & & \\
\hline
\end{tabular}




\begin{tabular}{|c|c|c|c|c|c|}
\hline & \multicolumn{2}{|c|}{$\begin{array}{l}\text { Ever Used Medical Services to } \\
\text { Achieve Pregnancy }\end{array}$} & \multicolumn{2}{|c|}{$\begin{array}{c}\text { Never Used Medical Services to } \\
\text { Achieve Pregnancy }\end{array}$} & \\
\hline & \multicolumn{2}{|c|}{$\mathrm{N}=1,824$} & \multicolumn{2}{|c|}{$\mathrm{N}=\mathbf{2 1 , 9 1 7}$} & \\
\hline & $\mathbf{N}$ & $\begin{array}{l}\text { Weighted \% } \\
\text { [95\% CI] }\end{array}$ & $\mathbf{N}$ & $\begin{array}{l}\text { Weighted \% } \\
\text { [95\% CI] }\end{array}$ & p-value \\
\hline $2 \$ 60,000$ & 768 & $51.0[47.5,54.5]$ & 5025 & $28.6[27.2,30.1]$ & \\
\hline \multicolumn{6}{|l|}{ Fecundity } \\
\hline Fecund & 600 & $34.9[31.5,38.2]$ & 15255 & $66.6[65.5,67.8]$ & $<0.0001$ \\
\hline Impaired Fecundity & 789 & $38.8[35.6,42.0]$ & 2128 & $9.6[9.0,10.2]$ & \\
\hline Surgically Sterile & 435 & $26.3[23.2,29.5]$ & 4534 & $23.8[22.7,24.9]$ & \\
\hline
\end{tabular}

${ }^{a}$ Gynecologic problems were defined as the presence of ovulation problems, uterine fibroids, or endometriosis 
Table 2.

Prevalence of using medical services to get pregnant by race/ethnicity among all women. ${ }^{a}$

\begin{tabular}{|c|c|c|c|c|}
\hline & $\begin{array}{l}\text { N Using } \\
\text { Services }\end{array}$ & $\begin{array}{c}\text { Weighted \% Using } \\
\text { Services }\end{array}$ & $\begin{array}{c}\text { Unadjusted } \\
\text { PPR [95\% CI] }\end{array}$ & $\begin{array}{c}\text { Adjusted } b \\
\text { PPR }[95 \% \text { CI] }\end{array}$ \\
\hline \multicolumn{5}{|l|}{ Any Services } \\
\hline White & 1393 & $9.6[8.9,10.4]$ & Reference & Reference \\
\hline Black & 258 & $5.1[4.2,5.9]$ & $0.53[0.44,0.63]$ & $0.77[0.64,0.92]$ \\
\hline American Indian/Alaska Native & 74 & $5.8[3.9,7.7]$ & $0.60[0.43,0.83]$ & $1.04[0.81,1.34]$ \\
\hline Asian/Pacific Islander & 80 & $9.9[6.6,13.1]$ & $1.02[0.74,1.41]$ & $1.08[0.83,1.41]$ \\
\hline Non-Hispanic & 1517 & $9.4[8.7,10.1]$ & Reference & Reference \\
\hline Hispanic & 307 & $5.3[4.5,6.1]$ & $0.57[0.48,0.67]$ & $0.94[0.79,1.12]$ \\
\hline \multicolumn{5}{|l|}{ Treatment $^{c}$} \\
\hline White & 736 & $52.9[49.2,56.6]$ & Reference & Reference \\
\hline Black & 94 & $41.2[33.0,49.4]$ & $0.78[0.63,0.97]$ & $0.98[0.80,1.21]$ \\
\hline American Indian/Alaska Native & 31 & $47.7[29.6,65.8]$ & $0.90[0.63,1.28]$ & $0.87[0.67,1.13]$ \\
\hline Asian/Pacific Islander & 30 & $47.1[29.1,65.2]$ & $0.89[0.61,1.29]$ & $1.00[0.75,1.33]$ \\
\hline Non-Hispanic & 774 & $52.9[49.4,56.4]$ & Reference & Reference \\
\hline Hispanic & 125 & $37.3[30.1,44.5]$ & $0.70[0.57,0.87]$ & $0.85[0.70,1.03]$ \\
\hline \multicolumn{5}{|l|}{ Testing } \\
\hline White & 851 & $61.8[58.2,65.4]$ & Reference & Reference \\
\hline Black & 112 & $47.3[37.9,56.7]$ & $0.77[0.63,0.93]$ & $0.84[0.68,1.03]$ \\
\hline American Indian/Alaska Native & 35 & $53.9[38.7,69.0]$ & $0.87[0.64,1.18]$ & $0.94[0.74,1.20]$ \\
\hline Asian/Pacific Islander & 43 & $62.8[47.2,78.4]$ & $1.02[0.80,1.30]$ & $1.08[0.88,1.32]$ \\
\hline Non-Hispanic & 903 & $61.7[58.2,65.3]$ & Reference & Reference \\
\hline Hispanic & 149 & $47.1[39.4,54.8]$ & $0.76[0.64,0.91]$ & $0.87[0.73,1.04]$ \\
\hline \multicolumn{5}{|l|}{ Advice } \\
\hline White & 1041 & $74.8[71.3,78.3]$ & Reference & Reference \\
\hline Black & 182 & $68.7[60.0,77.4]$ & $0.92[0.81,1.04]$ & $0.85[0.74,0.97]$ \\
\hline American Indian/Alaska Native & 55 & $76.0[59.6,92.4]$ & $1.02[0.85,1.22]$ & $1.04[0.85,1.27]$ \\
\hline Asian/Pacific Islander & 52 & $53.7[36.4,71.0]$ & $0.72[0.52,0.99]$ & $0.68[0.49,0.97]$ \\
\hline Non-Hispanic & 1132 & $73.5[70.0,77.1]$ & Reference & Reference \\
\hline Hispanic & 210 & $70.1[62.3,77.9]$ & $0.95[0.86,1.06]$ & $0.93[0.83,1.05]$ \\
\hline
\end{tabular}

Includes all women regardless of fertility problems

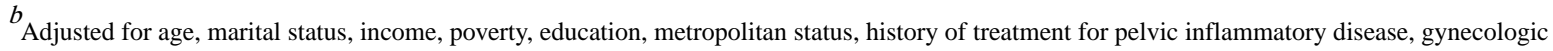
problems, religion, parity, current insurance, body mass index, and fecundity

${ }^{c}$ Treatment included drugs to improve ovulation, surgery to correct blocked tubes, artificial insemination, in vitro fertilization or other assisted reproduction, and surgery for endometriosis or fibroids. 
Table 3.

Prevalence of using any medical services to get pregnant by race/ethnicity for infertile women.

\begin{tabular}{|l|r|c|c|c|}
\hline \multicolumn{1}{|c|}{ Race/Ethnicity } & $\begin{array}{c}\text { N Using } \\
\text { Services }\end{array}$ & $\begin{array}{c}\text { Weighted \% Using } \\
\text { Services }\end{array}$ & $\begin{array}{c}\text { Unadjusted } \\
\text { PPR [95\% CI] }\end{array}$ & $\begin{array}{c}\text { Adjusted } \boldsymbol{a} \\
\text { PPR [95\% CI] }\end{array}$ \\
\hline White & 234 & $40.9[35.5,46.2]$ & Reference & Reference \\
\hline Black & 35 & $31.1[20.0,42.2]$ & $0.76[0.52,1.11]$ & $0.93[0.70,1.23]$ \\
\hline American Indian/Alaska Native & 19 & $39.8[19.8,59.9]$ & $0.98[0.58,1.63]$ & $1.31[0.88,1.95]$ \\
\hline Asian/Pacific Islander & 15 & $41.4[18.9,63.9]$ & $1.01[0.58,1.75]$ & $1.04[0.63,1.69]$ \\
\hline Non-Hispanic & 230 & $40.3[35.1,45.6]$ & Reference & Reference \\
\hline Hispanic & 80 & $36.1[26.9,45.4]$ & $0.90[0.67,1.19]$ & $\mathbf{1 . 3 3}[\mathbf{1 . 0 6 , 1 . 6 7}]$ \\
\hline
\end{tabular}

${ }^{a}$ Adjusted for age, marital status, income, poverty, education, metropolitan status, history of treatment for pelvic inflammatory disease, gynecologic problems, religion, parity, current insurance, and body mass index 
Table 4.

Prevalence of use of infertility services by race/ethnicity among all women. ${ }^{a}$

\begin{tabular}{|l|r|c|c|c|}
\hline & $\begin{array}{c}\text { N Using } \\
\text { Infertility } \\
\text { Services }\end{array}$ & $\begin{array}{c}\text { Weighted \% Using } \\
\text { Infertility Services }\end{array}$ & $\begin{array}{c}\text { Unadjusted } \\
\text { PPR [95\% CI] }\end{array}$ & $\begin{array}{c}\text { Adjusted } \boldsymbol{b} \\
\text { PPR [95\% CI] }\end{array}$ \\
\hline White & 1936 & $13.4[12.6,14.2]$ & Reference & Reference \\
\hline Black & 461 & $9.4[7.9,10.9]$ & $\mathbf{0 . 7 0}[\mathbf{0 . 6 0 , 0 . 8 3}]$ & $0.87[0.74,1.02]$ \\
\hline American Indian/Alaska Native & 137 & $10.4[7.6,13.2]$ & $\mathbf{0 . 7 8}[\mathbf{0 . 6 2 , 0 . 9 8}]$ & $1.14[0.93,1.40]$ \\
\hline Asian/Pacific Islander & 107 & $12.6[9.0,16.2]$ & $0.94[0.72,1.23]$ & $1.09[0.87,1.37]$ \\
\hline Non-Hispanic & 2159 & $13.2[12.4,14.0]$ & Reference & Reference \\
\hline Hispanic & 505 & $9.3[8.1,10.5]$ & $\mathbf{0 . 7 0}[\mathbf{0 . 6 1 , 0 . 8 1}]$ & $1.01[0.88,1.17]$ \\
\hline
\end{tabular}

${ }^{a}$ Use of any infertility services includes use of medical services to prevent miscarriage. This analysis also includes all women regardless of fertility problems.

${ }^{b}$ Adjusted for age, marital status, income, poverty, education, metropolitan status, history of treatment for pelvic inflammatory disease, gynecologic problems, religion, parity, current insurance, body mass index, and fecundity 